\title{
Second generation environmentalists
}

Environmental Issues: Population, Pollution and Economics. By Lawrence G. Hines. Pp. ix +339 . (Norton: New York, December 1973.) \$9.75 cloth; $\$ 3.25$ paper.

Society and the Assessment of Technology: Premises, Concepts, Methodology, Experiments, Areas of Application. By F. Hetman. Pp. 420 (OECD: Paris; HMSO: London, 1973.) 38 francs; £3.36; \$9.50.

Neither of these books is an original contribution to knowledge, but they are nevertheless both very useful. They reflect the extent to which environmental concerns and technology assessment have become part of normal policy making and analysis. The typical early literature of this genre had an evangelistic and strong emotional tone, which was often conveyed in the title as well as the text. One thinks, for example, of Our Plundered Planet, Silent Spring and the Population Bomb.

Both of these books belong emphatically to the second generation. Not that they are lacking in concern; Hines in particular makes quite explicit the strength of his attachment to the preservation of natural amenity and wilderness. But both are very much alive to the complexity of the issues and the trade-offs which are inevitably involved. This means that they are rather duller books than the best of the pioneering single-minded first generation advocacy; but as against this they are much more realistic and much more acceptable to administrators.

The scope of Hines's book is wider than that of Hetman's in one sense: its first section is devoted to the world population and resource problem brought into the limelight by the MIT "World Models". His sceptical critique of the MIT work, although much less thorough than that of the Sussex Science Policy Research Unit, comes to similar conclusions. The second part deals with problems of cost/benefit analysis and the third part with policies to combat pollution. Hetman's book does not discuss the "Limits to Growth" problem at all, nor does it discuss specific policies in relation to pollution. It is devoted entirely to a critical review of the various techniques of 'technology assessment' of which 'cost-benefit' is treated as one example.

Although there are important simi- larities, the books differ greatly in style and presentation. Hines's book is far better written, and does not suffer from poor translation into the curiously effete and de-humanised English jargon of the international bureaucracies. The Hines book is far better produced and edited, and the diagrams, tables and references are of a standard to which we have become accustomed in the best American college textbooks. The OECD publication by contrast is rather poorly produced and many of the tables are clumsy. Some of them (for example, Tables 15 and 16) are simply long quotations from other sources.

This is a misfortune as Hetman's book has some outstanding merits. It manages to synthesise a great deal of information about the burgeoning technology assessment movement. It is very balanced in its own assessment of the various techniques and sensible in its awareness of their strengths and limitations. It avoids the temptation of staking everything on one particular technique-a fault which bedevils so much of this literature. Finally it recognises the importance of the political process in relation to any technique or combination of them. In its allround grasp of a very complex problem the book compares very favourably with much of the American technology assessment literature. It is therefore a thousand pities that the book is so badly edited and produced. It is too long, often repetitive and sometimes unreadable. The two greatest faults are first: the inclusion of large chunks of material (especially in chapter 3) which should have been relegated to an appendix or the (otherwise excellent) reference list. Second, the failure to bring the book to life by thorough discussion of some reallife cases such as the third London airport or supersonic transport. Many examples are cited, but the form of citation is long enough to be boring but not thorough enough to give the full flavour and excitement of a real political problem. Perhaps these faults may be partly attributed to the inevitable limitations of publication through an international organisation, but the OECD has sometimes been outstanding in its toleration of lively and critical material (even when it was embarrassing to member governments) and in the quality of its publications.
By contrast, one of the best chapters in the Hines book is on the "Middle Snake River Hydro-electric Project". This makes the essential points far better than any theoretical analysis, since it shows so clearly just how cost-benefit analysis was manipulated in practice to serve particular interest groups, and the real practical difficulties involved in the attempt to put a market valuation on some of the intangibles. Hines is a competent professional economist but he has taken the trouble to learn a good deal about water and air pollution, and he therefore makes a modest success of his ambitious goal to transcend the normal disciplinary boundaries of economics. One must hope that this approach will become a new fashion in economics, either through interdisciplinary teams or by the individual efforts of men like Hines. He explains in a lucid, albeit very elementary manner, the failure of the market mechanism in decisions about the environment, and the inevitability of public responsibility and policy. In this respect, of course, his book is a welcome return to an old fashion: the original classical discipline was political economy.

C. FREEMAN

\section{Tetrahymena}

Biology of Tetrahymena. Edited by Alfred M. Elliott. Pp. x+508 (Dowden, Hutchinson and Ross: Stroudsburg, Pennsylvania; Wiley: Chichester, December 1973.) £19.25.

OF all the protozoa Tetrahymena is probably the most studied genus. $T$. pyriformis (formerly called Glaucoma pyriformis), which occurs in ponds and streams the world over, was first successfully cultivated axenically, that is, in the absence of the other organisms which comprise its normal diet, in 1923 by André Lwoff. By 1951 Kidder and Dewey had succeeded in growing it in a chemically defined, though very complex, medium. Later developments have been the discovery by Elliott and his colleagues of mating types of Tetrahymena, following similar work in Paramecium, thus opening up the possibilities of doing genetic work, and these have been exploited by Nanney, Allen and others. On technical grounds, however, Tetrahymena has turned out to be rather less suited to 